\title{
Uterine Rupture - Risk Factors and Pregnancy Outcome in Bundelkhand Region
}

\author{
Sheela Jain ${ }^{1}$ \\ ${ }^{1}$ Department of Obstetrics \& Gynaecology, Bundelkhand Medical College, Sagar, Madhya Pradesh, India.
}

\section{ABSTRACT}

\section{BACKGROUND}

Uterine rupture is defined as the tearing of the muscular wall of the uterus during pregnancy or labour. ${ }^{1}$ Often it occurs from the tearing of previous caesarean scar during labour. ${ }^{2}$ The other known risk factors for uterine rupture include, maternal age, height, body mass index (BMI), education, birth weight, gestational age, induction of labour, instrumental vaginal delivery, interpregnancy interval, congenital uterine anomaly, grand multiparity, previous uterine surgery, fetal macrosomia, fetal malposition, obstructed labour, uterine instrumentation, attempted forceps delivery, external version, and uterine trauma. ${ }^{2-6}$ This study was done to find out the prevailing risk factors associated with this grave condition in Bundelkhand region, so that mortality and morbidity associated with it could be prevented.

\section{METHODS}

We have studied 37 cases of uterine rupture, operated in our institution from Jan. 2018 to Oct. 2019. During this period a total of 2986 Caesarean sections (CS) were performed. Of these 37 cases, 5 were Nullipara (13.51\%), 16 primipara (31.25\%) and 16 were grand multipara (31.25\%). 24 cases (64.86 \%) had previous uterine scar while 13 (35.13\%) had no scar.

\section{RESULTS}

In our study major risk factors for uterine rupture were found to be previous scars (64.68 \%). Obstructive labour (23.07 \%), malpresentation (7.69\%), grand multiparity (38.46\%) and prolong labour (30.76\%), were responsible for rupture in unscarred uterus. In all cases we first tried to repair the tear and only 9 (24.32\%) needed hysterectomy. In our study 28 patients $(75.67 \%)$ required only repair whereas $24.32 \%$ cases needed hysterectomy. Maternal death was just 1 case $(2.7 \%)$ and (51.35\%) babies survived.

\section{CONCLUSIONS}

Majority of uterine rupture cases were found in women who had previous CS. So, first CS should be performed after very careful understanding of its indications. $2.7 \%$ maternal mortality and $51.35 \%$ delivery of live birth babies in our study proves that early detection and proper managing of the case can reduce maternal and fetal mortality in uterine rupture cases.

\section{KEY WORDS}

Uterine Rupture, Previous Scar, Inter-Pregnancy Interval
Corresponding Author:

Dr. Sheela Jain,

Associate Professor

Obstetrics \& Gynaecology,

Bundelkhand Medical College,

Sagar (M. P.), India.

E-mail:suprabh2013@gmail.com

DOI: $10.14260 /$ jemds/2021/403

How to Cite This Article:

Jain S. Uterine rupture - risk factors and pregnancy outcome in Bundelkhand region. $J$ Evolution Med Dent Sci 2021;10(27): 1961-1965, DOI:

10.14260/jemds/2021/403

Submission 06-02-2021,

Peer Review 07-05-2021,

Acceptance 13-05-2021,

Published 05-07-2021.

Copyright (c) 2021 Sheela Jain. This is an open access article distributed under Creative Commons Attribution License [Attribution 4.0 International (CC BY 4.0)] 


\section{BACKGROUND}

Uterine rupture is the full thickness disruption of the muscular wall of uterine. It also involves the overlying visceral peritoneum. On the basis of whether visceral peritoneum is involved or not, it may be complete (if visceral peritoneum is involved), or incomplete (also referred as uterine dehiscence), if visceral peritoneum is intact. Most commonly the muscular wall of the uterus tears during pregnancy or labour. ${ }^{1}$ Often it occurs from the tearing of previous caesarean scar during labour. ${ }^{2}$ The other known risk factors for uterine rupture include, maternal age, height, body mass index (BMI), education, birth weight, gestational age, induction of labour, instrumental vaginal delivery, interpregnancy interval, congenital uterine anomaly, grand multiparity, previous uterine surgery, fetal macrosomia, fetal malposition, obstructed labour, uterine instrumentation, attempted forceps delivery, external version, and uterine trauma. ${ }^{2-6}$ It is an obstetrical emergency associated with high maternal mortality and morbidity.

Although most uterine ruptures occur in women with prior scarred uterus, rupture of the nulliparous unscarred uterus also occurrs. Rupture of unscar uterus may be traumatic or spontaneous. Traumatic rupture may occur following abdominal trauma, assisted breach delivery, labour induction by prostaglandins or oxytocin, or instrumental delivery. Spontaneous uterine rupture, may occur but they are extremely rare, estimated to occur in one out of 8,000 to one of 15,000 deliveries. ${ }^{7}$ Spontaneous rupture may be associated with cephalopelvic disproportion, malpresentation, big baby, gross congenital abnormality of fetus, problem with normal expansion of uterus with progression of pregnancy like in unicornuate or bicornuate uterus, abnormal placental implantation.

In our country due to poverty and lack of education significant number of women do not have their regular antenatal checkup. Many a times they prefer home delivery by traditional birth attendants. They refer to well-equipped hospital very late in emergency situation after prolonged dysfunctional labour. Obstructed labour increases the risk of uterine rupture which is more in scarred uterus. ${ }^{8}$

There are no specific or universal clinical features for diagnosis of uterine rupture. But due to potential grave consequences of uterine rupture to both the mother and child, the obstetrician should have a high clinical suspicion for uterine rupture in the presence of severe or constant abdominal pain, vaginal bleeding, evidence of hypovolemia, loss of fetal station, and non-reassuring fetal heart rate patterns, fetal bradycardia and variable decelerations. Most common changes seen in the fetal heart rate patterns associated with uterine rupture are fetal bradycardia and late decelerations, occurring in up to $87.5 \%$ of cases. $^{9-13}$ Availability of cardiotocograph facility is very useful in detecting uterine rupture at a very early stage in high risk patients than continuous cardiotocograph monitoring during labour. Ultrasonography can be useful to find out disruption in uterine layers, detect hemoperitoneum, extrusion of fetus or placenta outside the uterine cavity. If fetus has come out from the uterus and is found within the peritoneal cavity, it is significantly associated with high morbidity and mortality.

We did this retrospective study to find out prevailing risk factors associated with this grave condition and the consequences of uterine rupture on maternal and perinatal outcome in our hospital, so that mortality and morbidity associated with it could be prevented.

\section{METHODS}

It is a retrospective observational study conducted on 37 cases of uterine rupture operated between Jan. 2018 and Oct. 2019, in the Department of Obstetrics and Gynaecology, Government Bundelkhand medical college, Sagar, Madhya Pradesh. We started this study after getting ethical clearance certificates from our institutional ethical committee. All the cases of ruptured uterus diagnosed clinically, by ultrasound or during surgery were included. Patients who either came directly to this institution or referred from primary care centers with this complication were also included in the study.

Age of the patients, detailed history of education level, antenatal visit, detailed obstetrical history, gravida and parity, interpregnancy interval, history of previous cesarian section, pregnancy factors such as prolonged or obstructed labour, induction of labour, malpresentation, use of instrumentation, and other factors such as patients direct visit to the hospital or referred through center were analysed in detail. Management of the cases whether repair or hysterectomy required and the maternal and fetal outcome was also studied in detail.

\section{RESULTS}

We have studied 37 cases of uterine rupture, during the said period during which total 2986 caesarian sections were performed. Of these 37 cases, 5 Nullipara (13.51\%), 16 primipara (31.25\%) and 16 were grand multipara (31.25\%). 30 women were in their reproductive age, while 7 were elderly, 6 were illiterate, 27 were literates but below $10^{\text {th }}$ standard and only 4 were educated up to or above $10^{\text {th }}$ standard. 13 cases had previous antenatal visit while 24 had no previous antenatal visit. 33 cases reached up to term pregnancy while 2 each had pre term and post term pregnancy. 31 cases delivered normal birth weight babies while 6 delivered low birth weight babies. 16 male and 21 female children were delivered. 6 cases came after attempted home delivery while 17 cases were referred from PHC whereas 14 cases came directly to our hospital for delivery, 24 cases (64.86\%) had previous uterine scar while 13 (35.13\%) cases had no scar.

\begin{tabular}{|cccc|}
\hline Sl. No & Causes & Number of Patients & Percentage \\
1 & Previous scar & N -24 & $64.68 \%$ \\
2 & Non scar & N -13 & $35.13 \%$ \\
\hline \multicolumn{4}{|c|}{ Table 1. Causes of Uterine Rupture } \\
\hline
\end{tabular}

\begin{tabular}{|cccc|}
\hline Sl. No & Causes & Number of Patients & Percentage \\
1 & Obstructed labour & $\mathrm{N}-3$ & $23.07 \%$ \\
2 & Malpresentation & $\mathrm{N}-1$ & $7.69 \%$ \\
3 & Grand multiparty & $\mathrm{N}-5$ & $38.46 \%$ \\
4 & Prolonged labour & $\mathrm{N}-4$ & $30.76 \%$ \\
\hline \multicolumn{4}{|c}{ Table 2. Causes of Rupture in Non Scar Uterus $\mathbf{( N - 1 3 )}$} \\
\hline
\end{tabular}

In 9 cases induction of labour was performed while in 28, no induction was performed. $15 \quad(46.87 \%)$ cases had interpregnancy interval < 18 months while 17 (53.12\%) cases 
had interpregnancy interval $>18$ months. 28 cases were managed by uterine repair while 9 required hysterectomy. We were able to save all but one case. 19 live babies and 18 IUD babies were delivered.

\begin{tabular}{|c|c|}
\hline Illiterate & Higher Secondary \\
\hline N- $513.51 \%$ & $\mathrm{~N}-38.10 \%$ \\
\hline \multicolumn{2}{|c|}{ Antenatal visit- } \\
\hline Yes & No \\
\hline $\mathrm{N}-13,35.13 \%$ & $\mathrm{~N}-24,64.86 \%$ \\
\hline \multicolumn{2}{|c|}{ Table 3. Socioeconomic Causes of Rupture } \\
\hline Repair & Hysterectomy \\
\hline $\mathrm{N}-28,75.67 \%$ & $\mathrm{~N}-9,24.32 \%$ \\
\hline \multicolumn{2}{|c|}{ Table 4. Management } \\
\hline
\end{tabular}

\begin{tabular}{|ccc|}
\hline & Live & Death \\
\hline Maternal & $\mathrm{N}-36,97.29 \%$ & $\mathrm{~N}-1,2.7 \%$ \\
Fetal & $\mathrm{N}-19,51.35 \%$ & $\mathrm{~N}-18,48.64 \%$ \\
\hline \multicolumn{3}{|c|}{ Table 5. Outcome of Uterine Rupture } \\
\hline
\end{tabular}

\section{DISCUSSION}

In our study major risk factors for uterine rupture were found to be previous scars (64.68\%). Obstructive labour (23.07 \%), malpresentation (7.69\%) grand multi parity (38.46\%), and prolonged labour (30.76\%), were responsible for rupture in unscarred uterus. Previous uterine scar was a single risk factor responsible for $64.68 \%$ of the cases. Therefore, close monitoring should be done while managing patients with previous uterine scar who are attempting trial of labor.

Previous caesarian section is responsible for majority of uterine scars. Worldwide caesarian section rate is increasing from $6.7 \%$ in 1990 to $19.1 \%$ in 2014 globally. ${ }^{14}$ Consequently, the number of deliveries by mothers with previous CS is also on the rise, After trial vaginal delivery in previous CS the incidence of uterine rupture is estimated to be less than $1 \%$ and success of vaginal delivery varies from 60 to $80 \% .{ }^{15}$ Ofir $\mathrm{K}^{1}$, Sheiner $\mathrm{E}$ et al. ${ }^{16}$ in their study found that the rate of uterine rupture was 50 times higher among women who had caesaren section in their first delivery, delivered vaginally in their subsequent deliveries, compared with women who experienced a spontaneous onset of delivery. They also found that induction of labour was associated with a doubled risk of uterine rupture both among women with a previous caesarean section and among women who did not have previous caesarean. In our study in 9 (24.32\%) women, induction of labour was performed. As we follow strict norm for induction of labour we did not make any correlation of uterine rupture with it.

$\mathrm{Al}$ - Zirqi,a,b B Stray et al. ${ }^{17}$ in their study found that Trial of labour carried increased risk of uterine rupture than elective repeated caesarean section, although absolute risks were low. As absolute risk of uterine rupture was not high in women with previous LSCS undergoing trial labour than elective repeat CS but relative risk of uterine rupture was high $^{18}$ Thus, proper selection and monitoring of patients who undergo trial of labour after the previous scar is a must.

David M Stamilio, ${ }^{1}$ Emily DeFranco et al. ${ }^{19}$ in their study found, increased association of uterine rupture with interpregnancy interval of less than 6 months. Emily A. DeFranco in his study, ${ }^{20}$ found that short interpregnancy interval was associated with increased risk of uterine rupture but this increased risk was only among those who had previous scars but no such risk was found, who had previous normal delivery. In our study 15 (40.54\%) women with previous scar had interpregnancy interval less than 18 months.

Carol N, B Denis ${ }^{21}$ found that women with previous LSCS and induction of labor were more prone to rupture than those who underwent spontaneous labor. ${ }^{20}$ Oxytocin and prostaglandins routinely used for induction of labour, ripen the cervix and increase uterine contraction. It may cause hyperstimulation of the uterus and may weaken scars from previous caesarean sections, leading to uterine rupture.

The incidence of spontaneous uterine rupture is extremely rare. In literature it is estimated to occur in one of 8,000 to one of 15,000 deliveries. ${ }^{22}$ In our study $35.13 \%$ of rupture occured in women with no previous scar. Of these obstructive labor (23.07\%), mal presentation (7.69\%), grand multiparity (38.46\%), prolonged labour (30.76\%) were responsible for uterine rupture in non scar uterus. It is similar to the findings of Vladimir Revicky, Aruna Muralidhar et al.22 that in the previous cesarean sections, multiparity, malpresentation and obstructed labor were major risk factors for uterine rupture.

Landon MB, Hauth JC et al. ${ }^{23}$ in their study found the relation between type of prior incision (low transverse, low vertical, classical, or other type) and risk of uterine rupture. They found that women with second gravida estimated uterine rupture rates as lowest for low transverse incisions and highest, for low vertical incisions. In our study all 24 women who had previous scar, was of low transverse type. Literature says that risk of rupture was much higher about 4 to $9 \%$ with a $\mathrm{T}$ - shaped or classical incision. As we routinely performed low transverse incision we could not make any significant correlation with type of incision and uterine rupture.

$(16.21 \%)$ home delivery attempted, (45.94\%), referred from PHC, (37.83 \%) directly came to institution. In our study there was no clear correlation between attempted home delivery and uterine rupture. It may be due to more and more of institutional delivery being promoted by the government.

$64.86 \%$ of patients do not have their previous antenatal checkup. This clearly correlates with the findings of Melaku Desta, Haile Amha, ${ }^{24}$ that absence of antenatal checkup has 8 fold higher risk of uterine rupture. Hence uterine ruptures are more prevalent among those who do not have regular antenatal checkup. In our study 31 (81.73\%) cases had birth weight between 2 to $3.5 \mathrm{~kg}$ and $6(16.21 \%)$ had low birth weight. No rupture was found with birth weight $>3.5$. This may be because we did not give any trial of vaginal delivery for those who had big babies with previous scar.

Uterine rupture is an emergency wherein early diagnosis and timely prompt intervention is required. Various surgical procedures like repair of the tear, subtotal or total hysterectomy can be performed depending upon the type, location, extension of tear and patient's general condition. Controversy exists among the authors whether repair of tear, subtotal or total hysterectomy is preferred as procedure of choice. ${ }^{25}$ Majority of authors recommend that surgical repair is a safer immediate treatment. ${ }^{26,27}$ In all cases we first tried to repair the tear and only $9(24.32 \%)$ were performed hysterectomy. In our study 28 patients $(75.67 \%)$ required only repair and $24.32 \%$ cases needed hysterectomy. 
In our study maternal death was just 1 case $(2.7 \%)$ and (51.35\%) babies survived. It is according to the findings of 0 W Yap' E S Kim ${ }^{28,29}$ that in an institution if close monitoring and timely intervention was taken, uterine rupture does not result in major maternal mortality and large number of neonates could survive. As our study was limited to the patients, only those were operated for uterine rupture and we did not study pregnant women in community hence a large number of women who were not able to reach the institution were missed in this study.

\section{CONCLUSIONS}

Our study is a small study, because we only studied the women who were operated for uterine rupture, so large number of neglected cases like those who were not able to reach the institution or were not diagnosed properly were wrongly left out. Because our hospital is government hospital situated in economically backward region of the country, so large bulk of the patients in this study belonged to average educated low socioeconomic group. Thus, this study does not reflect true problems in other groups of person. In spite of these short comings our study still concludes several important points. Majority of uterine rupture was found in women who had previous CS $-64.68 \%$. So, first CS should be performed after very careful understanding of its indications. $64.68 \%$ cases where uterine rupture occured in previous scar cases $40.54 \%$ had inter pregnancy interval less than 18 months. Hence in all the women in whom CS is performed, proper counselling and facility for spacing between pregnancies should be provided to them. $2.7 \%$ maternal mortality and $51.35 \%$ delivery of live birth babies in our study itself prove that early detection and by proper managing of the case we can reduce maternal and fetal mortality in uterine rupture cases.

Data sharing statement provided by the authors is available with the full text of this article at jemds.com.

Financial or other competing interests: None.

Disclosure forms provided by the authors are available with the full text of this article at jemds.com.

\section{REFERENCES}

[1] Murphy DJ. Uterine rupture. Curr Opin Obstet Gynecol 2006;18(2):135-40.

[2] Al-Zirqi I, Stray-Pedersen B, Forsen L, et al. Uterine rupture after previous caesarean section. An International Journal of Obstetrics and Gynaecology 2010;117(7):809-20.

[3] Smith D, Stringer E, Vladuitu CJ, et al. Risk of uterine rupture among women attempting vaginal birth after cesarean with an unknown uterine scar. Am J Obest Gynaecol 2015;213(1):80.e1-5.

[4] Kaczmarczyk M, Sparen P, Terry P, et al. Risk factors for uterine rupture and neonatal consequences of uterine rupture: a population-based study of successive pregnancies in Sweden. BJOG 2007;114(10):1208-14.
[5] Hofmeyr GJ, Say L, Gülmezoglu AM. WHO systematic review of maternal mortality and morbidity: the prevalence of uterine rupture. BJOG 2005;112(9):1221-8.

[6] Latika S. A 10 year analysis of uterine rupture at a teaching institution. J Obstet Gynecol India 2006;56(6):502-6.

[7] Miller DA, Goodwin TM, Gherman RB, et al. Intrapartum rupture of the unscarred uterus. Obstet Gynecol 1997;89(5 Pt 1):671-3.

[8] Mahbuba, Alam IP. Uterine rupture-experience of 30 cases at Faridpur medical college hospital. Faridpur Med Coll J 2012;7(2):79-81.

[9] Farmer RM, Kirschbaum T, Potter D, et al. Uterine rupture during trial of labor after previous cesarean section. Am J Obstet Gynecol 1991;165(4 Pt 1):996-100.

[10] Miller DA, Diaz FG, Paul RH. Vaginal birth after cesarean: a 10-year experience. Obstet Gynecol 1994;84(2):255-8.

[11] Nkemayim DC, Hammadeh ME, Hippach M, et al. Uterine rupture in pregnancy subsequent to previous laparoscopic electromyolysis. Case report and review of the literature. Arch Gynecol Obstet 2000;264(3):154-6.

[12] Leung AS, Leung EK, Paul RH. Uterine rupture after previous cesarean delivery: Maternal and fetal consequences. Am J Obstet Gynecol 1993;169(4):945-50.

[13] Betran AP, Ye J, Moller AB, et al. The increasing trend in caesarean section rates; global, regional and national estimates 1990-2014. PLoS One 2016;11(2):e0148343.

[14] Smith JG, Metz HL, Merril DC. Identifying risk fectors for uterine rupture. Clin Perinatal 2008;35(1):85-99.

[15] Landon MB, Hauth JC, Leveno KJ, et al. Maternal and perinatal outcomes associated with a trial of labor after prior cesarean delivery. $\mathrm{N}$ Engl J Med 2004;351(25):2581-9.

[16] Ofir K, Sheiner E, Levy A, et al. Uterine rupture: risk factors and pregnancy outcome. Am J Obstet Gynecol 2003;189(4):1042-6.

[17] Al-Zirqi I, Stray-Pedersen B, Forse'n L, et al. Uterine rupture after previous caesarean section. BJOG: An International Journal of Obstetrics and Gynaecology 2010;117(7):809-20.

[18] Stamilio DM, Defranco E, Pare E, et al. Short interpregnancy interval: risk of uterine rupture and complications of vaginal birth after cesarean delivery Obstet Gynecol 2007;110(5):1075-82.

[19] Defranco EA. 380: Risk of interpregnancy interval on uterine rupture: a population-based cohort study. American Journal of Obstetrics \& Gynecology 2016;214(Suppl 1).

[20] Lin C, Raynor BD. Risk of uterine rupture in labor induction of patients with prior cesarean section: an inner city hospital experience. Am J Obstet Gynecol 2004;190(5):1476-8.

[21] Gibbins KJ, Weber T, Holmgren CM, et al. Maternal and fetal morbidity associated with uterine rupture: unscarred uterus. Am J Obstet Gynecol 2015;213(3):382.e1-6.

[22] Revicky V, Muralidhar A, Mukhopadhyay S, et al. A case series of uterine rupture: lessons to be learned for future clinical practice. J Obstet Gynaecol India 2012;62(6):66573.

[23] Landon MB, Lynch CD. Optimal timing and mode of delivery after cesarean with previous classical incision or 
myomectomy: a review of the data. J Semin Perinatol 2011;35(5):257-61.

[24] Desta M, Amha H. Prevalence and predictors of uterine rupture among Ethiopian women: a systematic review and meta-analysis. PLoS One 2020;15(11):e0240675.

[25] Bruney TLM. Trends in surgical management of uterine rupture. Medical Research and Archives 2019;7(5):1-8.

[26] Sheth SS. Results of treatment of rupture of the uterus by suturing. J Obstet Gynaecol Br Commonw 1968;75(1):558.
[27] Nahum GG, Pham KQ. Uterine rupture in pregnancy. 2011 $\begin{array}{lll}\text { (Cited } 2008 & \text { Jan } \\ \text { http://emedicine.medscape.com/article/275854 }\end{array}$

[28] Yap W, Kim ES, Laros RK Jr. Maternal and neonatal outcomes after uterine rupture in labor. Am J Obstet Gynecol 2001;184(7):1576-81.

[29] ACOG practice bulletin no. 115: vaginal birth after previous cesarean delivery. Obstet Gynecol 2010;116(2 Pt 1):45-60. 